\begin{tabular}{|c|c|}
\hline Title & $\begin{array}{l}\text { Mathematical A nalysis of the Solidification Behavior of Plain Steel Based on Solute and Heat-Transfer Equations in } \\
\text { the Liquid-Solid Zone }\end{array}$ \\
\hline Author(s) & Fujimura, Toshio; Takeshita, Kunimasa; Suzuki, Ryosuke 0. \\
\hline Citation & $\begin{array}{l}\text { Metallurgical and Materials T ransactions B, 49(2), } 644-657 \\
\text { https://doi.org/10.1007/s11663-017-1149-8 }\end{array}$ \\
\hline Issue Date & $2018-04$ \\
\hline Doc URL & http:/hdl.handle.net/2115/76324 \\
\hline Rights & $\begin{array}{l}\text { This is a post-peer-review, pre copy edit version of an article published in [Metallurgical and materials transactions B]. } \\
\text { The final authenticated version is available online at: http://dx.doi.org/10.1007/s11663-017-1149-8. }\end{array}$ \\
\hline Type & article (author version) \\
\hline File Information & Mathematical A nalysis of the Solidification Behavior of Plain Steel Based on Solute-1.pdf \\
\hline
\end{tabular}

Instructions for use 


\title{
Mathematical Analysis of the Solidification Behavior of Plain Steel Based on Solute- and Heat-Transfer Equations in the Liquid-Solid Zone
}

\author{
Toshio Fujimura* \\ Audit\& Supervisory Board Member, \\ Rinko.co., \\ Iwamoto-chou 2-1-18, Chiyoda-Ku, \\ Tokyo,101-0032 Japan \\ Tel:+81-3-3864-2424 \\ Email: tomohio1000@gmail.com
}

Kunimasa Takeshita

Professor, Dr.,

Mechanical Engineering Course,

Graduate School of Engineering,

University of Fukui,

9-1 Bunkyo-3,Choume,Fukui,

Fukui,910-8507 Japan

Tel: +81-776-27-8530

FAX: $+81-776-27-8748$

Email: takeshita@u-fukui.ac.jp

Ryosuke O. Suzuki

Professor, Dr.,

Division of Materials Science and Engineering,

Faculty of Engineering,

Hokkaido University,

Kita-13 Jou, Nishi-8 Choume, Kita-Ku,

Sapporo, Hokkaido, 060-8628 Japan

Tel: +81-11-706-6339

FAX: +81-11-706-6342

Email: rsuzuki@eng.hokudai.ac.jp

$(*)$ Corresponding author

Toshio Fujimura

Email: tomohio1000@gmail.com 


\begin{abstract}
An analytical approximate solution to nonlinear solute- and heat-transfer equations in the unsteady-state mushy zone of $\mathrm{Fe}-\mathrm{C}$ plain steel has been obtained, assuming a linear relationship between the solid fraction and the temperature of the mushy zone. The heat transfer equations for both the solid and liquid zone along with the boundary conditions have been linked with the equations to solve the whole equations. The model predictions (e.g., the solidification constants and the effective partition ratio) agree with the generally accepted values and with a separately performed numerical analysis. The solidus temperature predicted by the model is in the intermediate range of the reported formulas. The model and Neumann's solution are consistent in the low carbon range. A conventional numerical heat analysis (i.e., an equivalent specific heat method using the solidus temperature predicted by the model) is consistent with the model predictions for Fe-C plain steels. The model presented herein simplifies the computations to solve the solute- and heat-transfer simultaneous equations while searching for a solidus temperature as a part of the solution. Thus, this model can reduce the complexity of analyses considering the heat- and solute-transfer phenomena in the mushy zone.
\end{abstract}

\title{
1 Introduction
}

Numerical methods are effectively used to simulate heat transfer phenomena during solidification processes. While these methods provide reliable surface temperatures (i.e., those calibrated with the measured values), inner temperatures, especially at the solidus point, are not generally confirmed with the actual (measured) values. The main reason for these problems lies in the difficulty [1] of achieving reliable results while measuring the solidus position during the casting process with an associated solidus temperature for general carbon steels. In addition, the fraction of solid in a solid-liquid coexisting zone (i.e., mushy zone) remains partly unknown.

With respect to the liquidus temperature, while it is not also generally measured during the casting process, the problems are not serious because micro-segregation at the dendrite tips is so small that super-cooling is limited only a few degrees. Therefore, the liquidus temperature for $\mathrm{Fe}-\mathrm{C}$ plain steel can be estimated from the phase diagram or from measurements which are in reasonable agreement with each other. However, with regard to the solidus temperature of steel, discrepancies exist between estimates of solidus temperature based on the phase diagram and models accounting for microsegregation. (i.e. $40 \mathrm{~K}$ discrepancies [2-5]). Recently, Gryc et al. [6] thermoanalytically measured 
the solidus temperature for various steel grades and reported significant discrepancies between the measurements and the values obtained from reported formulas (up to $42 \mathrm{~K}$ ) or thermodynamic calculations (up to $50 \mathrm{~K}$ ). These discrepancies could lead to considerable errors while estimating the position at which the shell develops with a target thickness.

The lack of knowledge about the fraction of solid in the mushy zone has spurred the onset of numerous methods based on heat analysis: (A) methods [7-9] assuming a linear relationship between the solid fraction and the temperature (e.g., equivalent specific heat model); (B) methods $[10,11]$ assuming the equilibrium lever rule, the Scheil equation, and back diffusion models such as the Brody-Flemings model [12] or the Clyne-Kurz [13] model; (C) methods [14] recovering the temperature with the latent heat release after solidification. However, these methods are not always consistent with the real solidification process. For example, (C) methods assume that the primary dendrites should grow after solidification. When the (B) methods are used along the dendrite axial direction, a flat boundary surface should be assumed for the dendritic mushy zone. When the (B) models are applied along to the normal to the dendrite axis direction (radial direction), diffusion along the dendrite axis direction should be neglected. However, diffusion along the primary dendrite axis is not negligible since the effective partition ratio of carbon is typically close to $0.9(0.85-1.0)$ for continuously cast steels [15]. Thus, the fraction of solid used in the thermal analysis should be consistent with general findings (e.g., solute diffusions along the primary dendrites axis) such that these heat analysis results are in line with general findings.

At the early stage of the solidification process (e.g., the chill zone), the issues mentioned above are not relevant because the mushy zone is not fully developed and because the solidus and liquidus surfaces are close together forming a substantially planar boundary.

At the middle stage of the solidification process, the mushy zone is fully developed, and the solidification process in this region should be taken into account. Asai et al. [16], Hills et al. [17], and Alexandrov et al. [18] obtained analytical or approximate analytical solutions assuming steady-state conditions (i.e., constant solidification velocity). However, these analytical solutions cannot be directly used for general solidification processes because the solidification velocity significantly changes with time. In addition, general thermal analysis assuming unsteady state solidification does not provide the data which are consistent with those obtained from the steady-state analyses.

In the case of unsteady state solidification at the middle stage, numerical analyzes are generally performed because of the difficulties to obtain the exact simultaneous solutions for the non-linear heat- and solutetransfer equations. Takeshita [19] obtained the simultaneous solutions for the $\mathrm{NH}_{4} \mathrm{Cl}$ aqueous eutectic 
system after analytically eliminating the solid fraction-related terms in the equations. Although extensive numerical computation was required to obtain the unknown solid fraction at the eutectic point where the solidus temperature and the solute concentration are given by the phase diagram, the solution was obtained as simultaneous solutions of the nonlinear heat- and solute-transfer equations.

Regarding the analytical solutions for unsteady state solidification, Huppert et al. [20] and Alexandrov [21] proposed models for aqueous chimney-type solidifications. However, these models focusing on a special case, such as a liquidus position develops exclusively while the solidus point hardly develops, cannot be applied for the solidification of general steels, because it is well known that the solidus point typically develops with the associated liquidus point during the solidification of general steels.

The approximate analytical solutions for a multi-component alloy system have been demonstrated by Fujimura et al. [22] solving the nonlinear heat- and solute-transfer equations with a moving coordinate system. The predicted effective partition ratios for a typical steel and shell thickness were in good agreement with the reported measurements. However, only the Dirichlet conditions (e.g., constant temperature and solute concentrations at the solidus point) at the boundaries have been assigned without adopting the boundary conditions generally used in heat analysis (i.e., Neumann-type boundary conditions). Consequently, this solution needs the measured solidification constants for the solidus and liquidus positions, and the accuracy of the model predictions strongly depends on the dispersion of these measurements. In addition, the results of the analysis cannot be directly linked with the thermal analysis results because of the insufficient boundary conditions.

To resolve these issues and obtain more reliable thermal analysis data, we expanded the analyzed regions to the entire system as compared to the previous model that considered only the mushy zone. The unknown solidification constants should be obtained as part of the solutions upon assigning the additional boundary conditions. A plain $\mathrm{Fe}-\mathrm{C}$ binary system is subjected to analysis since carbon is the dominant solute influencing the phase diagram. Additionally, the simplifications that help making a model as simple as possible have been adopted.

\section{Mathematical Model}

\subsection{Solidification Problems}

The solidification problems mathematically modeled and the volume element studied are schematically shown in Fig.1. Heat is unidirectionally extracted and a solid shell is considered to grow from the surface. In the mushy zone, heat and solute are considered to transfer by conduction and diffusion, respectively. 
The main assumptions made in the model formulation, which are in agreement with the previous model [22] for multicomponent alloy systems, are as follows:

(1) Heat is exclusively extracted by heat conduction along the primary dendrite axis (i.e., $\mathrm{x}$ axis) direction.

(2) The density and specific heat of the liquid are the same as those of the solid in a mushy zone.

(3) The solute is exclusively transported by diffusion via moderate fluid flow in the mushy zone.

(4) The dependency of the equilibrium partition ratio and the solute interdiffusion coefficient on the solute concentration is negligible.

(5) The effect of the dendrite tip curvature on the liquidus temperature is negligible.

(6) Undercooling within the mushy zone is negligible.

(7) The diffusion of the solute, carbon, in the liquid within the mushy zone is sufficiently rapid to achieve a homogeneous composition in the direction normal to that of the heat extraction (i.e., primary dendrite radial direction) over a distance in the order of the primary dendrite arm spacing. Generally, the magnitude of the primary dendrite arm spacing in cast steels (continuously cast or into static ingot) is in the range of 50-500 $\mu \mathrm{m}$ except in the chill zone.

(8) Local equilibrium between the liquid and the solid surfaces in the volume element is achieved (This assumption was also considered by Asai et al., [16] Takeshita [19], Huppert et al. [20] and Fujimura et al. [22]).

(9) As considered in conventional heat analysis, the fraction of solid in the mushy zone is assumed to be linear to the temperature.

From the mathematical point of view, the heat- and solute-transfer equations should be simultaneously solved for the liquid and solid in the mushy zone which are subjected to the boundary conditions of the moving solidus and liquidus boundaries at initial conditions. However, the problem can be simplified upon the assumption that the boundary values (i.e., temperature and solute concentration) are constant. The same assumption was previously made by Asai et al. [16], Takeshita [19], and Fujimura et al. [22]. Another important methodology of the models is achieved by the assumption (8) as follows: If the models (B) mentioned before (i.e., the equilibrium lever rule) are adopted in the volume element, the solidus temperature should be that dictated on the solidus line of the phase diagram with the initial bulk liquid concentration (Fig. 1, c-f temperature line). On the other hand, the solidus temperature is obtained on the liquidus line of the phase diagram liquidus line where the residual liquid completes the solidification (Fig. $1, \mathrm{~b}-\mathrm{e}$ temperature line). This is the key methodology of the model which was adopted in many models 
$[16,19,20,22]$.

In the following analysis, the diffusion of the solute along the primary dendrite axis direction (i.e., $x$ axis) resulting the dilution of the solute in the mushy zone is considered, and the solute- and heat-transfer equations will be simultaneously solved.

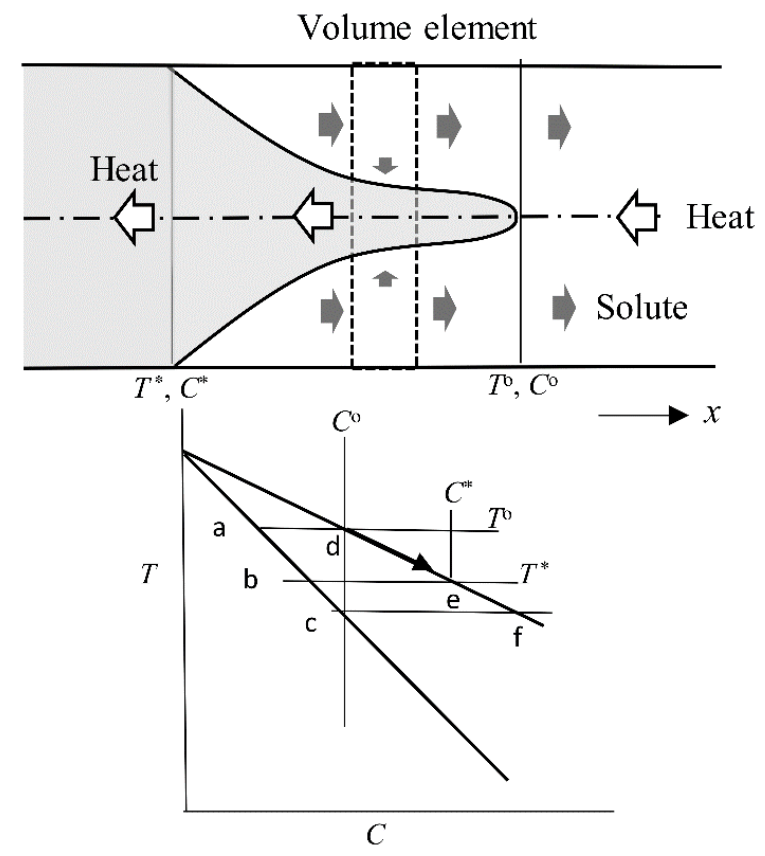

Fig. 1 Schematic of the solidification problem under study.

\subsection{Mathematical Formulations}

The preconditions and assumptions made in the model are as follows, which correspond to three zones, [I] solid zone, [II] mushy zone, and [III] liquid zone, are as follows:

[ I zone]

The liquid initially held at $T^{\mathrm{i}}$ is instantaneously kept at $T^{\mathrm{s}}$ at the surface $(x=0)$ and solidification begins.

(II) As is typical of continuously cast steels, the thickness of the cast steel is large.

[ II zone ]

(II1) The objective steel is $\mathrm{Fe}-\mathrm{C}$ binary steel.

(II2) The liquidus temperature is coupled with the solute concentration by the liquidus surface of the phase diagram that can be represented by the following equation, as proposed by Kawawa et al. [23].

$T=T_{\mathrm{M}}+\mathrm{mC}$

$T_{\mathrm{M}}$ : Solidus temperature of pure liquid (K) 
$\mathrm{m}$ : Temperature gradient of the liquidus line with respect to the solute concentration $(\mathrm{K} / \%)$

$C$ : Solute concentration (\%) of the liquid in the mushy zone.

(II3) A linear relationship between the liquid fraction $f$ and the temperature $T$ is assumed as follows:

$$
f=\frac{T-T^{*}}{T^{0}-T^{*}}
$$

$T^{\mathrm{o}}$ : Liquidus temperature

$T^{*}$ : Solidus temperature

The following equation is obtained using Eqs. (1) and (2):

$$
f=\lambda C+s
$$

By the definition of solid fraction $f_{s}$ and $f$, one obtains:

$$
\begin{aligned}
& 1=f+f_{s} \\
& f_{s} \quad \text { : fraction solid } \\
& \lambda 、 s: \text { unknown constants } \\
& \text { (II3) } \left.T=T^{*} \text { at I / II boundary ( } x=x^{*} \text { solidus point }\right) \\
& \text { (II4) } T=T^{\mathrm{o}} \text { at II / IIIboundary }\left(x=x^{\mathrm{o}} \text { liquidus point }\right)
\end{aligned}
$$

\section{[ III zone ]}

The liquid temperature at the center of cast steel is assumed to remain constant at $T^{\mathrm{i}}$ (as will be discussed later, the numerical analysis showed that this assumption is practically reasonable). We denote the solute concentration at the liquidus and solidus positions as $C^{\circ}$ and $C^{*}$, respectively, and the following equations are obtained:

At the liquidus point:

$$
\begin{gathered}
1=\lambda C^{\mathrm{o}}+s: x=x^{\mathrm{o}}, f=1 \\
T^{\mathrm{o}}=T_{\mathrm{M}}+\mathrm{m} C^{\mathrm{o}}: x=x^{\mathrm{o}}, T=T^{\mathrm{o}}, C=\mathrm{C}^{\mathrm{o}}
\end{gathered}
$$

At the solidus point:

$$
\begin{aligned}
& 0=\lambda C^{*}+s \quad: x=x^{*}, f=0 \\
& T^{*}=T_{\mathrm{M}}+\mathrm{m} C^{*}: x=x^{*}, T=T^{*}, C=C^{*}
\end{aligned}
$$

Combining Eqs. (4)-(8), the following equations are obtained:

$$
\begin{aligned}
& \lambda=\frac{\mathrm{m}}{T^{0}-T^{*}} \\
& s=\frac{T_{\mathrm{M}}-T^{*}}{T^{0}-T^{*}}
\end{aligned}
$$


The density, the specific heat, and the thermal conductivity of each zone are referred as $\rho_{\mathrm{i}}, C p_{\mathrm{i}}, K_{\mathrm{i}}$ (i represents the zone), while L represents the latent heat. The heat balance equations are as follows in the three zones.

\section{[I zone ]}

$$
\begin{aligned}
\rho_{1} C p_{1} \frac{\partial T}{\partial t} & =K_{1} \frac{\partial^{2} T}{\partial x^{2}} \\
x & =0 \quad: T=T^{\mathrm{S}} \\
x & =x^{*}: T=T^{*}
\end{aligned}
$$

[ II zone ]

$$
\begin{array}{r}
\rho_{2} C p_{2} \frac{\partial T}{\partial t}+\rho_{2} L \frac{\partial f}{\partial t}=K_{2} \frac{\partial^{2} T}{\partial x^{2}} \\
x=x^{*} \quad: T=T^{*} \\
x=x^{\mathrm{o}} \quad: T=T^{\mathrm{o}}
\end{array}
$$

By substituting 2) in 14) we obtain:

$$
\left\{\rho_{2} C p_{2}+\rho_{2} L /\left(T^{\circ}-T^{*}\right)\right\} \frac{\partial T}{\partial t}=K_{2} \frac{\partial^{2} T}{\partial x^{2}}
$$

The Neumann's boundary Eq. (24) is needed if mushy zone does not exist. The heat accumulation by the conduction at the interface and the latent heat generation due to the moving of interface should be related to the velocity of moving interface. However, the boundary conditions are simplified as are used in the conventional heat analysis for the present case.

$$
\begin{aligned}
& -\left.K_{1} \frac{\partial T}{\partial x}\right|_{x^{*}}+\left.K_{2} \frac{\partial T}{\partial x}\right|_{x^{*}}=0 \\
& -\left.K_{2} \frac{\partial T}{\partial x}\right|_{x^{\circ}}+\left.K_{3} \frac{\partial T}{\partial x}\right|_{x^{\circ}}=0
\end{aligned}
$$

[ III zone ]

$$
\begin{aligned}
\rho_{3} C p_{3} \frac{\partial T}{\partial t} & =K_{3} \frac{\partial^{2} T}{\partial x^{2}} \\
t & =0 \quad: T=T^{\mathrm{i}} \\
x & =x^{\mathrm{O}}: T=T^{\mathrm{O}}
\end{aligned}
$$

These equations are transformed with the similarity variables defined as Eqs. (23),(24) and (25) that are conventionally used to yield the ordinary differential equations as shown below. It should be noted that these transformations fit well with an infinite molten liquid. However, the thickness of the continuously cast steel is generally large enough to yield constant temperature at the central region of the slab. 


$$
\begin{gathered}
\eta_{1}=\frac{x}{2 \sqrt{\beta_{1} t}} \\
\eta_{2}=\frac{x}{2 \sqrt{\beta_{2} t}} \\
\eta_{3}=\frac{x}{2 \sqrt{\beta_{3} t}} \\
\beta_{1}=\frac{K_{1}}{\rho_{1} C p_{1}} \\
\beta_{2}=\frac{K_{2}}{\rho_{2} C p_{2}+\frac{\rho_{2} L}{\left(T^{\circ}-T^{*}\right)}} \\
\beta_{3}=\frac{K_{3}}{\rho_{3} C p_{3}}
\end{gathered}
$$

The following ordinary differential equations and solutions in three zones are obtained by the above transformations.

[ I zone ]

$$
\begin{aligned}
-2 \eta_{1} \frac{\mathrm{d} T}{\mathrm{~d} \eta_{1}}=\frac{\mathrm{d}^{2} T}{\mathrm{~d} \eta_{1}{ }^{2}} & \\
x=0 & \eta_{1}=0 \quad: T=T^{\mathrm{s}} \\
x=x^{*} & \eta_{1}=\eta_{1}^{*} \quad: T=T^{*} \\
T=\frac{\left(T^{*}-T^{\mathrm{s}}\right)}{\operatorname{erf}\left(\eta_{1}^{*}\right)} \operatorname{erf}\left(\eta_{1}\right)+T^{\mathrm{s}} &
\end{aligned}
$$

[ II zone ]

$$
\begin{gathered}
-2 \eta_{2} \frac{\mathrm{d} T}{\mathrm{~d} \eta_{2}}=\frac{\mathrm{d}^{2} T}{\mathrm{~d} \eta_{2}^{2}} \\
x=x^{*} \quad \eta_{2}=\eta_{2}^{*} \quad: T=T^{*} \\
x=x^{\mathrm{o}} \quad \eta_{2}=\eta_{2}^{\mathrm{o}} \quad: T=T^{\mathrm{o}} \\
T=\frac{\left(T^{*}-T^{\mathrm{o}}\right)\left\{\operatorname{erf}\left(\eta_{2}\right)-\operatorname{erf}\left(\eta_{2}^{\mathrm{o}}\right)\right\}}{\left\{\operatorname{erf}\left(\eta_{2}^{*}\right)-\operatorname{erf}\left(\eta_{2}^{\mathrm{o}}\right)\right\}}+T^{\mathrm{o}}
\end{gathered}
$$

[ III zone ]

$$
\begin{aligned}
-2 \eta_{3} \frac{\mathrm{d} T}{\mathrm{~d} \eta_{3}} & =\frac{\mathrm{d}^{2} T}{\mathrm{~d} \eta_{3}^{2}} & \\
t & =0 \quad \eta_{3}=\infty & : T=T^{i} \\
x & =x^{\mathrm{o}} \quad \eta_{3}=\eta_{3}^{\mathrm{o}} & : T=T^{\mathrm{O}}
\end{aligned}
$$




$$
\begin{gathered}
x=x^{\mathrm{c}} \eta_{3}=\eta_{3}^{c} \quad: T=T^{\mathrm{c}} \approx T^{\mathrm{i}} \\
T=\frac{\left(T^{\mathrm{o}}-T^{i}\right)\left\{1-\operatorname{erf}\left(\eta_{3}\right)\right\}}{\left\{1-\operatorname{erf}\left(\eta_{3}^{\mathrm{o}}\right)\right\}}+T^{i}
\end{gathered}
$$

where $T^{\mathrm{c}}\left(\eta_{3}{ }^{\mathrm{c}}\right) \approx T^{i}$ because $\eta_{3}{ }^{\mathrm{c}}$ at the center of the slab is kept large in a general continuous casting (i.e. the temperature drop of $T^{\mathrm{c}}$ is few degrees as shown in the later chapter).

Note that the following $T^{\infty}$ obtained from Eq. (36) by adopting $\eta_{2}=\infty$ was the extrapolated temperature out the range of the zone (II). This $T^{\infty}$ will be used in the later chapter.

$$
T^{\infty}=\frac{\left(T^{*}-T^{\mathrm{o}}\right)\left\{1-\operatorname{erf}\left(\eta_{2}^{\mathrm{o}}\right)\right\}}{\left\{\operatorname{erf}\left(\eta_{2}^{*}\right)-\operatorname{erf}\left(\eta_{2}^{\mathrm{o}}\right)\right\}}+T^{\mathrm{o}}
$$

\subsection{Heat and Solute Transportations in the Mushy Zone}

The solute discharged from the growing solid is transferred to the solidification direction (along the primary dendrite axis direction) by diffusion. The diffusivity, inter-diffusion coefficient, of the solute in the solid was referred as $D$ while that in the liquid is denoted as $E$.

The variation of the solute concentration within a volume element with respect to time is given by:

$$
\frac{\partial\left(f C+f_{s} \bar{C}_{s}\right)}{\partial t}=\frac{\partial}{\partial x}\left\{E f \frac{\partial C}{\partial x}\right\}+\frac{\partial}{\partial x}\left\{D f_{s} \frac{\partial \bar{C}_{s}}{\partial x}\right\}
$$

$C_{\mathrm{s}} \quad$ : solute concentration of the solid surface, which is in equilibrium with the liquid

$\bar{C}_{\mathrm{s}}$ : averaged solute concentration in solid

The variation of the solute concentration in the solid (i.e., the second term of the left-hand of Eq. (43) is given by using the parameter $\alpha$ :

$$
\frac{\partial\left(f_{\mathrm{s}} \bar{C}_{\mathrm{s}}\right)}{\partial t}=C_{\mathrm{s}} \frac{\partial f_{\mathrm{s}}}{\partial t}+f_{\mathrm{s}} \frac{\partial\left(\alpha C_{\mathrm{s}}\right)}{\partial t}
$$

where $\alpha$ is a parameter [16] having a value of 0 or 1 that defines the diffusion limits in the solid (i.e., $\alpha=$ 0 when the diffusion of the solute in the solid is negligible and $\alpha=1$ when the diffusion in the solid, such as the case of carbon, is rapid enough to result in homogeneous composition over distances in the order of the primary dendrite diameter).

$C_{\mathrm{s}}$ is related to $C$ with the partition ratio k by the following equation:

$$
C_{\mathrm{s}}=\mathrm{k} C
$$


Substituting Eqs. (4), (44), and (45) into (43) yields:

$$
\frac{\partial\{f(1-\alpha \mathrm{k}) C+\alpha \mathrm{k} C\}}{\partial t}=E \frac{\partial}{\partial x}\left\{f \frac{\partial C}{\partial x}\right\}+\alpha \mathrm{k} D \frac{\partial}{\partial x}\left\{(1-f) \frac{\partial C}{\partial x}\right\}
$$

Transforming with Eq. (24) provides the following ordinary equation.

$$
\begin{aligned}
& \{\lambda(2-\mathrm{k}-\alpha \mathrm{k}\} C+s(1-\alpha \mathrm{k})+\alpha \mathrm{k}\}\left(-2 \eta_{2} \beta_{2}\right) \frac{\mathrm{d} C}{\mathrm{~d} \eta_{2}} \\
& =\lambda(E-\alpha \mathrm{k} D)\left(\frac{\mathrm{d} C}{\mathrm{~d} \eta_{2}}\right)^{2}+\{\lambda(E-\alpha \mathrm{k} D) C+s(E-\alpha \mathrm{k} D)+\alpha \mathrm{k} D\} \frac{\mathrm{d}^{2} C}{\mathrm{~d} \eta_{2}^{2}}
\end{aligned}
$$

Substituting Eq. (1) to the heat balance Eq. (33) gives

$$
-2 \eta_{2} \frac{\mathrm{d} C}{\mathrm{~d} \eta_{2}}=\frac{\mathrm{d}^{2} C}{\mathrm{~d} \eta_{2}{ }^{2}}
$$

The boundary conditions Eqs. (34) and (35) can be characterized as follows:

$$
\begin{array}{ll}
\text { at } x=x^{*} & \eta_{2}=\eta_{2}^{*}, C=C^{*}, f=0 \\
\text { at } x=x^{\mathrm{o}} & \eta_{2}=\eta_{2}^{\mathrm{o}}, C=C^{\mathrm{o}}, f=1
\end{array}
$$

To simultaneously solve Eqs. (47) and (48), the unknown constants are determined to match both the first-order differential equation obtained by Eq. (48) and that obtained by eliminating the second-order differential terms from Eq. (47). Integrating Eq. (48) twice with Eqs. (49) and (50) yields

$$
C=\frac{\left(C^{*}-C^{\mathrm{o}}\right)\left\{\operatorname{erf}\left(\eta_{2}\right)-\operatorname{erf}\left(\eta_{2}^{\mathrm{o}}\right)\right\}}{\left\{\operatorname{erf}\left(\eta_{2}^{*}\right)-\operatorname{erf}\left(\eta_{2}^{\mathrm{o}}\right)\right\}}+C^{\mathrm{o}}
$$

Differentiating Eq. (51) gives

$$
\frac{\mathrm{d} C}{\mathrm{~d} \eta_{2}}=\frac{\left(C^{*}-C^{\mathrm{o}}\right)}{\left\{\operatorname{erf}\left(\eta_{2}^{*}\right)-\operatorname{erf}\left(\eta_{2}^{\mathrm{o}}\right)\right\}} \cdot \frac{2 \exp \left(-\eta_{2}^{2}\right)}{\sqrt{\pi}}
$$

Eliminating the second-order differential terms from Eqs. (47) and (48) and defining the constants $F^{\mathrm{o}}$ and $G^{\circ}$ as follows yields

$$
\begin{aligned}
\frac{\mathrm{d} C}{\mathrm{~d} \eta_{2}}= & \left(-2 \eta_{2}\right)\left(F^{\circ} C+G^{\mathrm{o}}\right) \\
F^{\circ} & =\frac{(2-\mathrm{k}-\alpha \mathrm{k})}{(E-\alpha \mathrm{k} D)} \beta_{2}-1 \\
G^{\circ} & =\frac{s}{\lambda}\left\{\frac{(1-\alpha \mathrm{k})}{(E-\alpha \mathrm{k} D)} \beta_{2}-1\right\}+\frac{\alpha \mathrm{k}\left(\beta_{2}-D\right)}{\lambda(E-\alpha \mathrm{k} D)}
\end{aligned}
$$

Substituting Eq. (51) into (53) gives 


$$
\frac{\mathrm{d} C}{\mathrm{~d} \eta_{2}}=\left(-2 \eta_{2}\right)\left[\left[\frac{\left(C^{*}-C^{\mathrm{o}}\right)\left\{\operatorname{erf}\left(\eta_{2}\right)-\operatorname{erf}\left(\eta_{2}^{\mathrm{o}}\right)\right\}}{\left\{\operatorname{erf}\left(\eta_{2}^{*}\right)-\operatorname{erf}\left(\eta_{2}{ }^{\mathrm{o}}\right)\right\}}+C^{\mathrm{o}}\right] F^{\mathrm{o}}+G^{\mathrm{o}}\right]
$$

The following equation is a good approximation [22] of the error-function of $\eta$ for large $\eta$ (Appendix I).

$$
\operatorname{erf}(\eta) \approx 1-\frac{\exp \left(-\eta^{2}\right)}{\eta \sqrt{\pi}}
$$

Adopting this approximation to Eq. (56) yields

$$
\frac{\mathrm{d} C}{\mathrm{~d} \eta_{2}}=F^{\mathrm{o}} \frac{\left(C^{*}-C^{\mathrm{o}}\right)}{\left\{\operatorname{erf}\left(\eta_{2}^{*}\right)-\operatorname{erf}\left(\eta_{2}^{\mathrm{o}}\right)\right\}} \cdot \frac{2 \exp \left(-\eta_{2}^{2}\right)}{\sqrt{\pi}}-\left(2 \eta_{2}\right)\left[\left[\frac{\left(C^{*}-C^{\mathrm{o}}\right)\left\{1-\operatorname{erf}\left(\eta_{2}^{\mathrm{o}}\right)\right\}}{\left\{\operatorname{erf}\left(\eta_{2}^{*}\right)-\operatorname{erf}\left(\eta_{2}^{\mathrm{o}}\right)\right\}}+C^{\mathrm{o}}\right] F^{\mathrm{o}}+G^{\mathrm{o}}\right]
$$

The followings equations are obtained to match Eq. (52) with (58).

$$
\begin{aligned}
& F^{\mathrm{o}}=1 \\
& {\left[\frac{\left(C^{*}-C^{\mathrm{o}}\right)\left\{1-\operatorname{erf}\left(\eta_{2}^{\mathrm{o}}\right)\right\}}{\left\{\operatorname{erf}\left(\eta_{2}^{*}\right)-\operatorname{erf}\left(\eta_{2}^{\mathrm{o}}\right)\right\}}+C^{\mathrm{o}}\right] F^{\mathrm{o}}+G^{\mathrm{o}}=0}
\end{aligned}
$$

Substituting Eq. (59) into (54) results in

$$
\beta_{2}=\frac{2(E-\alpha \mathrm{k})}{(2-\mathrm{k}-\alpha \mathrm{k})}
$$

Substituting Eq. (27) into (9) gives

$$
\lambda_{2}=\frac{\mathrm{m}}{\rho_{2} L}\left(\frac{K_{2}}{\beta_{2}}-\rho_{2} C p_{2}\right)
$$

Substituting Eq. (62) into (5) gives

$$
s=1-\frac{\mathrm{m}}{\rho_{2} L}\left(\frac{K_{2}}{\beta_{2}}-\rho_{2} C p_{2}\right)
$$

Note that $\beta_{2}, \lambda$, and $s$ satisfy Eqs. (27), (9) and (10). $C^{*}$ is obtained using Eqs. (7), (62) and (63) as follows:

$$
C^{*}=C^{\circ}-\frac{1}{\frac{\mathrm{m}}{\rho_{2} L}\left(\frac{K_{2}}{\beta_{2}}-\rho_{2} C p_{2}\right)}
$$

$C_{\mathrm{s}}^{*}$ is obtained with Eq. (45) as follows:

$$
C_{\mathrm{S}}^{*}=\mathrm{k} C^{*}
$$


Assuming the concentration of the solute at the liquidus position is equal to that of bulk liquid, $T^{\mathrm{o}}$ and $T$ *are obtained by Eq. (6) and (8). The condition (60) which closes the simultaneous equations, is formulated using Eqs. (1) and (42) as follows:

$$
\left[\frac{\left(T^{*}-T^{\mathrm{o}}\right)\left\{1-\operatorname{erf}\left(\eta_{2}^{\mathrm{o}}\right)\right\}}{\left\{\operatorname{erf}\left(\eta_{2}^{*}\right)-\operatorname{erf}\left(\eta_{2}^{\mathrm{o}}\right)\right\}}+T^{\mathrm{o}}-T_{\mathrm{M}}\right] \frac{F^{\mathrm{o}}}{\mathrm{m}}+G^{\mathrm{o}}=\left(T^{\infty}-T_{\mathrm{M}}\right) \frac{F^{\mathrm{o}}}{\mathrm{m}}+G^{\mathrm{o}}=0
$$

where $F^{\mathrm{o}}=1$ as shown in Eq. (59), $G^{\mathrm{o}}$ is expressed in terms of $T^{*}$ by substituting Eqs. (9), (10), and (61) into Eq. (55) and $T^{\infty}$ is expressed in terms of $T^{*}, \eta_{2}{ }^{*}, \eta_{2}{ }^{\mathrm{o}}$ and $T^{*}$ as in Eq.(41). Substituting these $G^{\mathrm{o}}, F^{\mathrm{o}}$, and $T^{\infty}$ into Eq.(66) gives the following equation which shows the requirement for three unknown constants $\eta_{2}{ }^{*}, \eta_{2}{ }^{\mathrm{o}}$ and $T^{*}$,

$$
\frac{T^{\infty}-T^{\circ}}{T^{*}-T^{\circ}}=\frac{\left\{1-\operatorname{erf}\left(\eta_{2}^{\circ}\right)\right\}}{\left\{\operatorname{erf}\left(\eta_{2}^{*}\right)-\operatorname{erf}\left(\eta_{2}^{\circ}\right)\right\}}=\frac{2(1-\mathrm{k})}{(2-\mathrm{k}-\alpha \mathrm{k})} C^{\circ} \lambda+\frac{(1+\alpha \mathrm{k}) \mathrm{k}}{(2-\mathrm{k}-\alpha \mathrm{k})}-\frac{\alpha \mathrm{k} D}{E-\alpha \mathrm{k} D}
$$

where $\lambda$ is given with $T^{*}$ using Eq. (9). It should be noted that $E$ in the right-hand of Eq. (67) should satisfy the following equation given by Eqs. (27) and (61).

$$
\frac{2(E-\alpha \mathrm{k})}{(2-\mathrm{k}-\alpha \mathrm{k})}=\frac{K_{2}}{\rho_{2} C p_{2}+\frac{\rho_{2} L}{T^{\circ}-T^{*}}}
$$

Eqs. (23),(24), and (25) give the following expressions:

$$
\begin{aligned}
& \eta_{2}^{*}=\sqrt{\frac{\beta_{1}}{\beta_{2}}} \eta_{1}^{*} \\
& \eta_{2}^{\mathrm{o}}=\sqrt{\frac{\beta_{3}}{\beta_{2}}} \eta_{3}^{\mathrm{o}}
\end{aligned}
$$

Substituting Eqs. (32), (36), (41), and (69) and (70) into the boundary conditions, Eqs. (18) and (19) gives

$$
\begin{aligned}
& \frac{K_{1}\left(T^{*}-T^{\circ}\right) \exp \left\{\left(1-\frac{\beta_{2}}{\beta_{1}}\right)\left(\eta_{2}^{*}\right)^{2}\right\}}{\left(T^{*}-T^{\circ}\right) \operatorname{erf}\left(\sqrt{\frac{\beta_{2}}{\beta_{1}}} \eta_{2}^{*}\right) \sqrt{\beta_{1}}}=\frac{K_{2}}{\left\{\operatorname{erf}\left(\eta_{2}^{*}\right)-\operatorname{erf}\left(\eta_{2}^{\circ}\right)\right\} \sqrt{\beta_{2}}} \\
& \frac{K_{3}\left(T^{i}-T^{\circ}\right) \exp \left\{\left(1-\frac{\beta_{2}}{\beta_{3}}\right)\left(\eta_{2}^{\circ}\right)^{2}\right\}}{\left(T^{*}-T^{\circ}\right)\left\{1-\operatorname{erf}\left(\sqrt{\frac{\beta_{2}}{\beta_{3}}} \eta_{2}^{\circ}\right\} \sqrt{\beta_{3}}\right.}=\frac{K_{2}}{\left\{\operatorname{erf}\left(\eta_{2}^{*}\right)-\operatorname{erf}\left(\eta_{2}^{\circ}\right)\right\} \sqrt{\beta_{2}}}
\end{aligned}
$$

Three unknown constants $T^{*}, \eta_{2}{ }^{*}$, and $\eta_{2}{ }^{o}$ are easily fixed to match Eqs. (67), (71), and (72) with the 
try and error method (the process is shown in Appendix II), where $K_{1}, K_{2}, K_{3}, \beta_{1}$, and $\beta_{3}$ are given by the reported physical properties, and $T^{\mathrm{i}}, T^{\mathrm{s}}$, and $T^{\mathrm{o}}$ are given as initial conditions. The liquidus temperature $T^{\circ}$ is estimated with the reported formula [23] and both $\beta_{2}$ and $\lambda$ are expressed in terms of $T^{*}$ by Eqs. (27) and (9). It should be noted that the third term in the right-hand of Eq. (67) is negligible because $D$ is significantly smaller than $E$. Consequently, the three equations exclusively involve the three unknown constants $\left(T^{*}, \eta_{2}{ }^{*}\right.$ and $\left.\eta_{2}{ }^{\circ}\right)$, such that these unknown constants should be able to be fixed. Fixing the three unknown constants takes several minutes by manual calculation with spreadsheets or, alternatively, it can be instantly obtained if the algorithm shown in Appendix II is used either with a personal or a tablet computer.

The interdiffusion coefficient $E$ is estimated with Eq. (61) or Eq. (68) after closing the simultaneous equations (i.e., after fixing $T^{*}, \eta_{2}{ }^{*}$, and $\eta_{2}{ }^{\circ}$ ). The interdiffusion coefficient $\mathrm{D}$ in the solid is referred to reported measurements. Finally, the solidus and liquidus positions $x^{*}$ and $x^{0}$, respectively, as a function of time are given by Eq. (24) with $\eta_{2}{ }^{*}$ and $\eta_{2}{ }^{o}$ as follows:

$$
\begin{gathered}
x^{*}=2 \eta_{2}^{*} \sqrt{\beta_{2} t} \\
x^{\mathrm{o}}=2 \eta_{2}^{\mathrm{o}} \sqrt{\beta_{2} t}
\end{gathered}
$$

Thus, the heat- and solute-transfer equations are simultaneously solved without the measured solidification constants (as required in the previous model [22]. The fractions of solid in the mushy zone are predicted by Eq. (2). The temperature in the solid, mushy, and liquid zones are predicted with Eqs. (32), (36), and (41), respectively. The solute concentration in the mushy zone is also predicted with Eq. (1) or (51). It should be noted that the predicted solidus temperature $T^{*}$ is determined as a part of the simultaneous solutions.

\section{Model Validations and Discussions}

\subsection{Physical Properties}

The physical properties used in the model are listed in Table 1. The values selected for the thermal conductivity in the mushy zone warrants discussion because the measurements have not been made under the conditions corresponding to this solid-liquid region, particularly with respect to the fluid flow.

Thermally driven flow adjacent to the solidification front can give rise to estimated velocities of $0.001-$ $0.01 \mathrm{~m} / \mathrm{s}[8,25]$ while solidification shrinkage may generate a fluid velocity of $0.001 \mathrm{~m} / \mathrm{s}$ [26-28]. Consequently, the thermal conductivity in the mushy zone could be larger than that measured in a stagnant liquid. However, this difference is not expected to be great because heat flow via conduction is 
larger as compared to convection at the low fluid velocities used herein. Moreover, a significant fraction of solid of the mushy zone consisted of fixed solid dendrites unaffected by the fluid flow. Thus, the thermal conductivities [29] measured under stagnant conditions, were used in the present model. The same argument does not hold when considering the interdiffusion coefficients in the interdendritic liquid because the rate of solute transport by diffusion is low as compared to convection. Hence, the interdiffusion coefficients measured in a stagnant liquid cannot be used for the interdendritic region. However, the diffusivity and interdiffusion coefficients of carbon can be estimated with Eq. (68). This approach used herein was also employed in the previous model [22]. The estimated interdiffusion coefficient, including the influence of the fluid flow, should be greater than the values measured under stagnant conditions.

In general, a molten steel at a temperature of around $1812 \mathrm{~K}\left(1539{ }^{\circ} \mathrm{C}\right)$ is poured into a water-cooled mold. Initial solidification begins upon chilling with the water cooled mold and subsequent cooling by water spraying. The slab surface temperature is generally measured with optical instruments generally installed in the lower positions of a caster because of the facility restrictions. Under such circumstances, Meng et al. [30] performed a reliable and continuous measurements of a continuously cast $0.45 \% \mathrm{C}$ steel by means of a thermocouples with a block fed into a mold. Considering their analysis, the surface temperature is assumed to remain at $1423 \mathrm{~K}\left(1150^{\circ} \mathrm{C}\right)$ during solidification. The molten steel super-heat (i.e., the over heat of the bulk liquid against the liquidus temperature) was assumed to be $15 \mathrm{~K}\left(15^{\circ} \mathrm{C}\right)$ as is common for a general continuously cast steel.

The influence of the carbon partition ratio on the solidus temperature is high while the reported carbon partition ratios $\mathrm{k}$ for a $\delta$ phase are in the range of $0.13-0.29[31,32]$ except for the low carbon steel $(0.023 \% \mathrm{C})$. The representative value $[33,34]$ of this range $(\mathrm{k}=0.225)$ was used in this model. This $\mathrm{k}$ value can be changed as discussed in later chapters. 
Table 1 Physical properties employed in the model

\begin{tabular}{|c|c|c|c|}
\hline & \multicolumn{2}{|r|}{ Property } & Value \\
\hline \multirow{4}{*}{$\begin{array}{c}\text { I } \\
\text { zone }\end{array}$} & $\rho_{1}$ & density & $7.7 \times 10^{3} \mathrm{Kg} / \mathrm{m}^{3}$ \\
\hline & $C p_{1}$ & specific heat & $0.77 \mathrm{~kJ} / \mathrm{kgK}$ \\
\hline & $K_{1}$ & thermal conductivity & $30.6 \mathrm{~W} / \mathrm{mK}$ \\
\hline & $L$ & heat of fusion & $276 \mathrm{~kJ} / \mathrm{kg}$ \\
\hline \multirow{5}{*}{$\begin{array}{c}\text { II } \\
\text { zone }\end{array}$} & $\rho_{2}$ & density & $7.5 \times 10^{3} \mathrm{Kg} / \mathrm{m}^{3}$ \\
\hline & $\mathrm{Cp}_{2}$ & specific heat & $0.77 \mathrm{~kJ} / \mathrm{kgK}$ \\
\hline & $K_{2}$ & thermal conductivity & $31.8 \mathrm{~W} / \mathrm{mK}$ \\
\hline & $\mathrm{k}$ & partition ratio of $\mathrm{C}$ in $\delta-\mathrm{Fe}$ & $0.225^{[33,34]}$ \\
\hline & $D$ & interdiffusion coefficients of solid & $6.6 \times 10^{-10} \mathrm{~m} 2 / \mathrm{sec}^{[40]}$ \\
\hline \multirow{3}{*}{$\begin{array}{c}\text { III } \\
\text { zone }\end{array}$} & $\rho_{3}$ & density & $7.4 \times 10^{3} \mathrm{Kg} / \mathrm{m}^{3}$ \\
\hline & $\mathrm{Cp}_{3}$ & specific heat & $0.77 \mathrm{~kJ} / \mathrm{kgK}$ \\
\hline & $K_{3}$ & thermal conductivity & $31.8 \mathrm{~W} / \mathrm{mK}$ \\
\hline \multicolumn{3}{|c|}{ Liquidus temperature $^{[23]}$} & $T^{\circ}=1809-78(\% \mathrm{C})-4.9(\% \mathrm{Mn})-7.6(\% \mathrm{Si}) \quad \mathrm{K}$ \\
\hline
\end{tabular}

\subsection{Thermal Analysis}

The temperature transition of a plain steel $(0.15 \% \mathrm{C})$ slab with $0.22 \mathrm{~m}$ in thickness as predicted by the present model after $240 \mathrm{~s}$ lapse from the solidification start is shown in Fig. 2. The surface $T^{\mathrm{s}}$ and initial $T^{\mathrm{i}}$ temperatures were 1423 and $1812 \mathrm{~K}\left(1150\right.$ and $\left.1539^{\circ} \mathrm{C}\right)$ (superheat $\Delta T=15 \mathrm{~K}\left(15^{\circ} \mathrm{C}\right)$ ), respectively. The thickness of the mushy zone was $1.4 \times 10^{-2} \mathrm{~m}$ and the solidification constants for the solidus and liquidus points were $2.55 \times 10^{-3}$ and $3.44 \times 10^{-3} \mathrm{~m} / \mathrm{s}^{1 / 2}$, respectively, which are in the range of generally accepted values $[1,15]$. The temperature gently decreased from the center of the slab to the liquidus point. Subsequently, the slope increased toward the solidus point while smoothly passing the solidus point.

The numerical heat analysis was separately performed (shown by a dashed line). The consistencies with respect to the solidus and liquidus points between the analytical solutions and the numerical heat analysis were examined by using the solidus temperature $T^{*}$ estimated by the present model. The conventional equivalent specific heat method (according to the procedure by Katayama et al. [35]) and the upwind finite difference methods were adopted in the numerical analysis, assuming a linear relationship between the solid fraction and the temperature, as assumed in the model. The boundary conditions (3.18), (3.19), and the symmetric condition at the center region of the slab were adopted. 
As shown in Fig. 2, the analytical solutions and the numerical analysis were in good agreement with respect to the temperature and both the solidus and liquidus positions. Better agreements were obtained upon increasing the partitioning of the objective slab (e.g., the accuracy of the solidus point obtained by the numerical analysis was less than $0.3 \%$ with a partitioning of 4000 for a half thickness slab).

Concerning to the drop of temperature in the center region, it was estimated to be $3 \mathrm{~K}\left(3{ }^{\circ} \mathrm{C}\right)$ with the numerical analysis, and this value is within the accuracy range of the temperature measurements [36]. Consequently, the assumption of constant temperature at the center of the slab made in the model formulations was reasonable, at least it should be allowed from the practical viewpoint.

It should be noted that a conventional numerical heat analysis that satisfies the solute-transfer equation needs extensive computation to search for the solidus temperature with the associated solid fraction in a mushy zone which is obtained by the model while accounting for the heat and solute balances in a large quantity of volume elements.

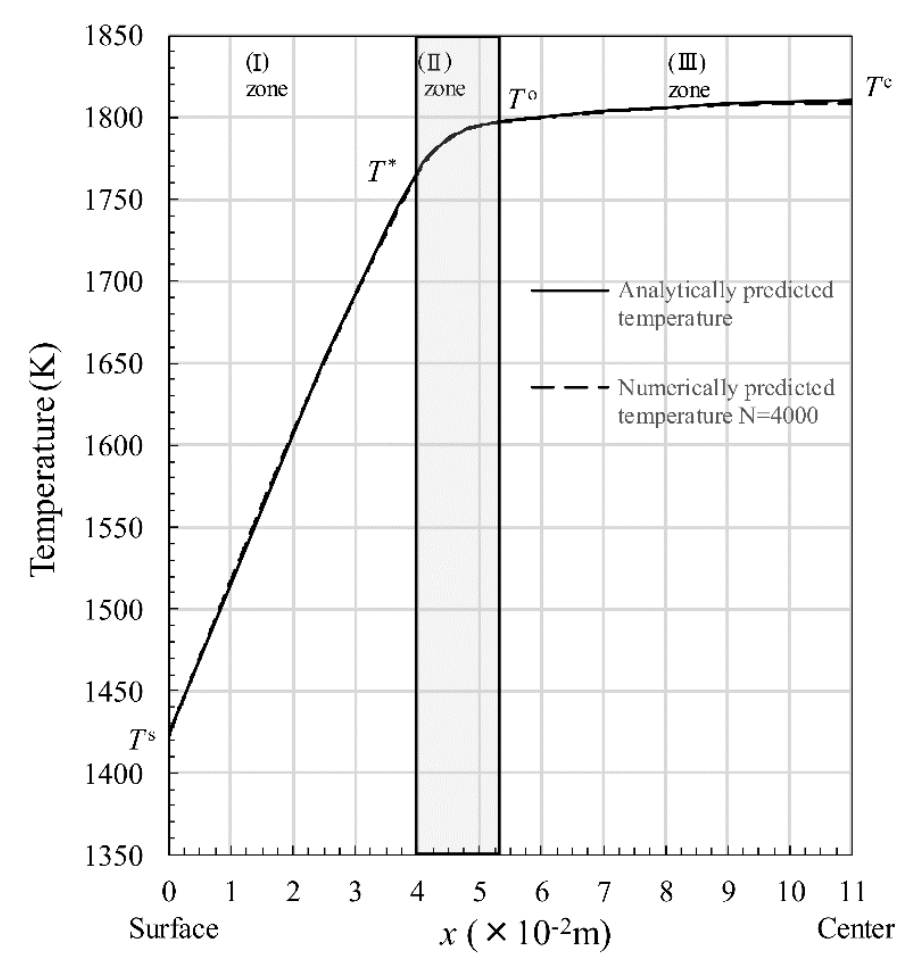

Fig. 2 Temperature distributions predicted by the model and numerical analysis of a continuously cast steel. $(0.15 \% \mathrm{C}$, $T^{\mathrm{s}}=1423 \mathrm{~K}\left(1150^{\circ} \mathrm{C}\right), \Delta T=15 \mathrm{~K}\left(15^{\circ} \mathrm{C}\right), t=240 \mathrm{~s}$, slab thickness $=0.22 \mathrm{~m}, \mathrm{~N}=$ partitioning number of the half thickness of a slab).

\subsection{Material Analysis}


The transition of the solute concentration and the liquid fraction in the mushy zone predicted by the model is shown in Fig. 3. The estimated carbon interdiffusion coefficient $E$ for a $0.15 \% \mathrm{C}$ steel was 3.8 $\times 10^{-7} \mathrm{~m}^{2} / \mathrm{s}$ which was in good agreement with the reported values by Asai et al. [16] $\left(4.7 \times 10^{-7} \mathrm{~m}^{2} / \mathrm{s}\right)$ and by Fujimura et al. [22] $\left(3.98 \times 10^{-7} \mathrm{~m}^{2} / \mathrm{s}\right)$ estimated for a Fe- $0.15 \% \mathrm{C}-0.70 \% \mathrm{Mn}-0.22 \% \mathrm{Si}$ continuously cast steel. Although the estimated interdiffusion coefficient obtained by the model was somewhat larger than that measured by Grace et al. [37] $\left(2-4 \times 10^{-7} \mathrm{~m}^{2} / \mathrm{s}\right)$ under stagnant conditions, this is reasonable as discussed earlier.

The carbon concentration at the solidus point (defined as $C / C^{\circ}$ ) predicted by the present model was 3.9 and was in good agreement with that estimated by the previous model [ 22] for a $0.15 \% \mathrm{C}$ low-alloyed steel $\left(C / C^{\mathrm{o}}=3.8\right)$. The effective carbon partition ratio $\mathrm{k}^{\mathrm{ef}}(0.89)$ was in the range of reported findings [15], $\mathrm{k}^{\mathrm{ef}}=0.9(0.85-1.0)$. Moreover, as shown in Fig. 3, a good agreement between the numerical solute analysis by directly solving Eq. (43) with the $C^{*}$ and $T^{*}$ values estimated by the model (long dashed line) and those predicted from the conventional heat analysis using the solidus temperature $\mathrm{T}^{*}$ estimated by the model (carbon concentration was estimated by Equation (1), thin solid line) was obtained. Thus, conventional heat analysis such as the equivalent specific heat method using the solidus temperature estimated by the model provides the solutions not only for the temperature but also for the solute concentrations. Thus, the present model is considered to simplify the extensive computations required to simultaneously solve the heat- and solute-transfer equations while searching the solidus temperature and the fraction solid as part of simultaneous solution.

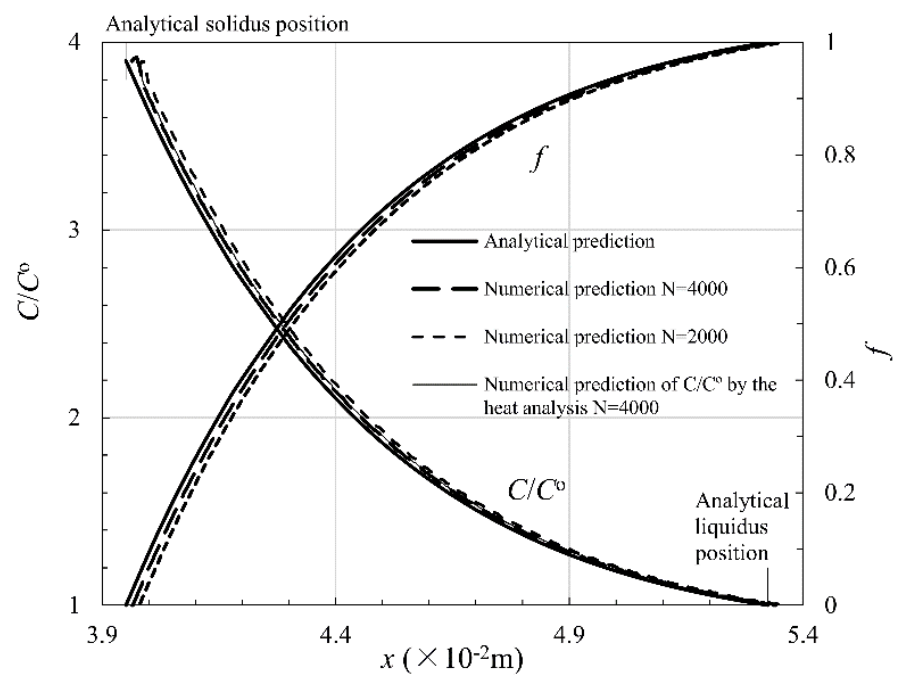

Fig. 3 Solute concentration $C / C^{0}$ and liquid fraction predicted by the model and numerical analysis of a continuously cast steel. $\left(0.15 \% \mathrm{C}, T^{\mathrm{s}}=1423 \mathrm{~K}\left(1150^{\circ} \mathrm{C}\right), \Delta T=15 \mathrm{~K}\left(15^{\circ} \mathrm{C}\right), t=240\right.$ s, slab thickness $=0.22 \mathrm{~m}, \mathrm{~N}=$ partitioning number of the half thickness of a slab). 


\subsection{Comparisons with Neumann's solution}

The temperature transitions in the mushy zone predicted by the model and the Neumann's solution ${ }^{24)}$ for pure iron are shown in Fig. 4. Again, the surface temperature was kept at $1423 \mathrm{~K}\left(1150^{\circ} \mathrm{C}\right)$ and the superheat of the initial temperature $(\Delta T)$ was $15 \mathrm{~K}\left(15^{\circ} \mathrm{C}\right)$ for all cases. Accordingly, the initial temperature for the low carbon steels was higher than that of the high carbon steels to keep the same superheat $(\Delta T)$. As shown in Fig. 4, the temperature profile approached that of the Neumann's solution as the carbon concentration decreased. The changes in the solidification constants of the solidus and liquidus points with respect to the carbon concentration are shown in Fig. 5. The solidification constants of the solidus point increased and that of liquidus decreased while decreasing the carbon concentration. These values converged with the Neumann's solution for carbon concentration lower than $0.025 \%$. The errors of the solidus temperature $T^{*}$ in the process shown in Appendix II exceeded $0.1 \mathrm{~K}\left(0.1^{\circ} \mathrm{C}\right)$ at carbon concentrations lower than $0.025 \%$, and this should be considered the limitation to use the model. However, this convergence of the model predictions with the Neumann's solution [24] is indicative of a good consistency between the model and the Neumann's solution at low carbon range.

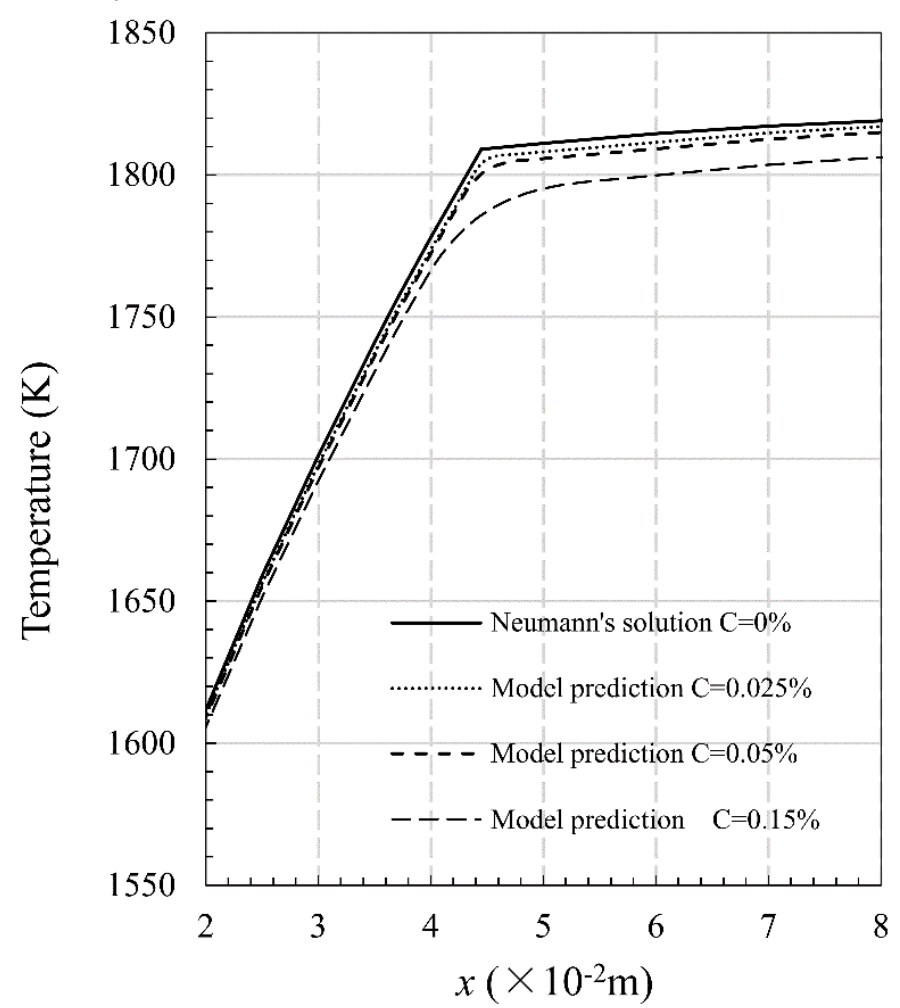

Fig. 4 Transitions of temperature predicted by the model and the Neumann' solution $(C=0 \%)$ of a continuously cast steel. $\left(\mathrm{C}=0 \%-0.15 \%, T^{\mathrm{s}}=1423 \mathrm{~K}\left(1150^{\circ} \mathrm{C}\right), \Delta T=15 \mathrm{~K}\left(15^{\circ} \mathrm{C}\right), t=240 \mathrm{~s}\right.$, slab thickness $\left.=0.22 \mathrm{~m}\right)$. 


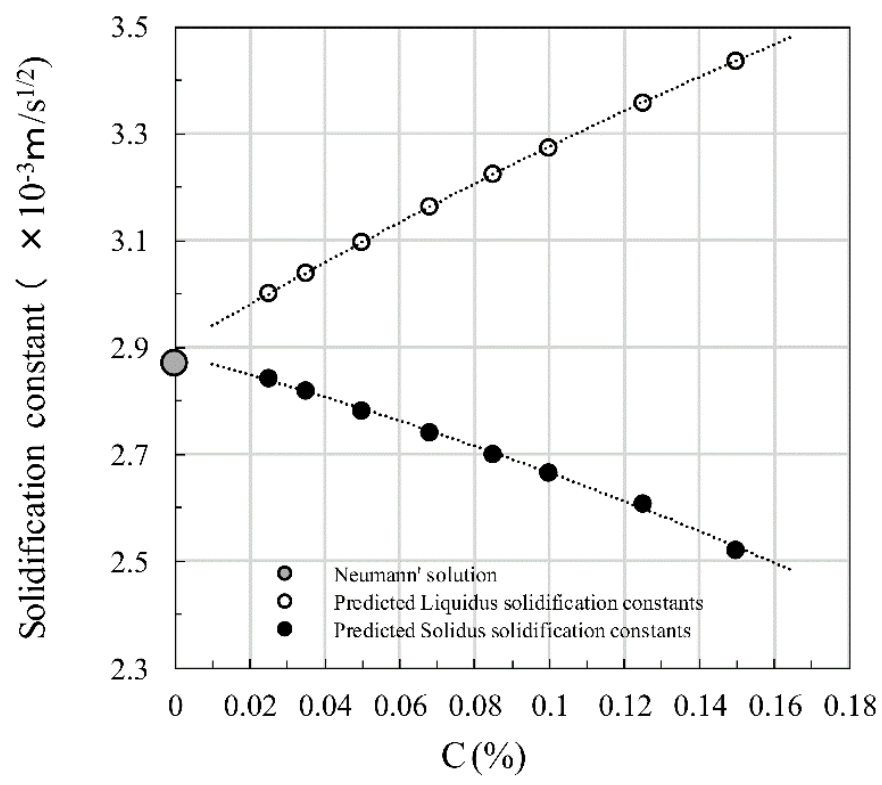

Fig. 5 Predicted liquidus and solidus solidification constants and the Neumann's solution of a continuously cast steel. $\left(0.025 \%-0.15 \% \mathrm{C}, T^{\mathrm{s}}=1423 \mathrm{~K}\left(1150^{\circ} \mathrm{C}\right), \Delta T=15 \mathrm{~K}\left(15^{\circ} \mathrm{C}\right), t=240 \mathrm{~s}\right.$, slab thickness $\left.=0.22 \mathrm{~m}\right)$.

\subsection{Solidus Temperature}

As shown earlier, the solidus temperature $T^{*}$ was obtained by matching the three of Eqs. (67), (71), and (72) with a set of $T^{*}, \eta_{2}{ }^{*}$, and $\eta_{2}{ }^{\circ}$. However, this $T^{*}$ can be explicitly given by Eq. (68) as follows:

$$
T^{*}=T^{\circ}-\frac{L}{\frac{(2-\mathrm{k}-\alpha \mathrm{k}) K_{2}}{2 \rho_{2}(E-\alpha \mathrm{k} D)}-C p_{2}}
$$

The solidus temperature $T^{*}$ estimated with Eq. (75) exactly matches with the set of solutions satisfying Eqs. (67), (71), and (72). It should be noted that the inter-diffusion coefficient $E$ for the liquid used in Eq. (75) is given by Eq. (68).

The evolution of the solidus temperature $T^{*}$ and the estimated $E$ as the physical properties changed by $1 \%$ are shown in Table 2 . The estimated $E$ value changes almost evenly with the heat conductivity $\mathrm{K}_{2}$, while the influence of the carbon partition ratio $\mathrm{k}$ is prominent as compared with other independent physical properties. The solidus temperatures estimated with different carbon partition ratios $\mathrm{k}$ and those calculated with other reported formulas are shown in the $\mathrm{Fe}-\mathrm{C}$ binary phase diagram (Fig. 6). The solidus temperatures estimated by the model are represented with solid lines while dotted lines correspond to the approximation errors of Eq. (57) exceeding 1\% for the higher carbon concentration range. The solidus temperatures estimated by the model exist in the intermediate range between those calculated with formulas by Hirai et al. [3] and Suzuki et al. [4] and those calculated by Kawawa et al. 
[2] and Jablonka et al. [5] The colored area seems to be reasonable because the effective partition ratio is larger than 0.85 as in the case of a real continuously cast steel (mostly close to 0.9 ) and the approximation errors remain lower than $1 \%$. The solidus temperature predicted by the model is 10 and $20 \mathrm{~K}$ higher than that calculated with the Kawawa's formula [2] for a Fe- $0.15 \% \mathrm{C}$ steel when $\mathrm{k}=0.19$ and $\mathrm{k}=0.225$ are used, respectively.

Table 2 Effect of an increase of $1 \%$ in the parameters over $T^{*}$ and $E$.

\begin{tabular}{|c|c|c|}
\hline & $\Delta T^{*}(\mathrm{~K})$ & $\Delta E(\%)$ \\
\hline $\mathrm{K}_{2}$ & -0.0072 & 1.02 \\
\hline$\rho_{2}$ & -0.044 & -0.86 \\
\hline $\mathrm{Cp}_{2}$ & -0.041 & -0.2 \\
\hline $\mathrm{L}$ & -0.042 & -0.93 \\
\hline $\mathrm{k}$ & 4.161 & -1.43 \\
\hline
\end{tabular}

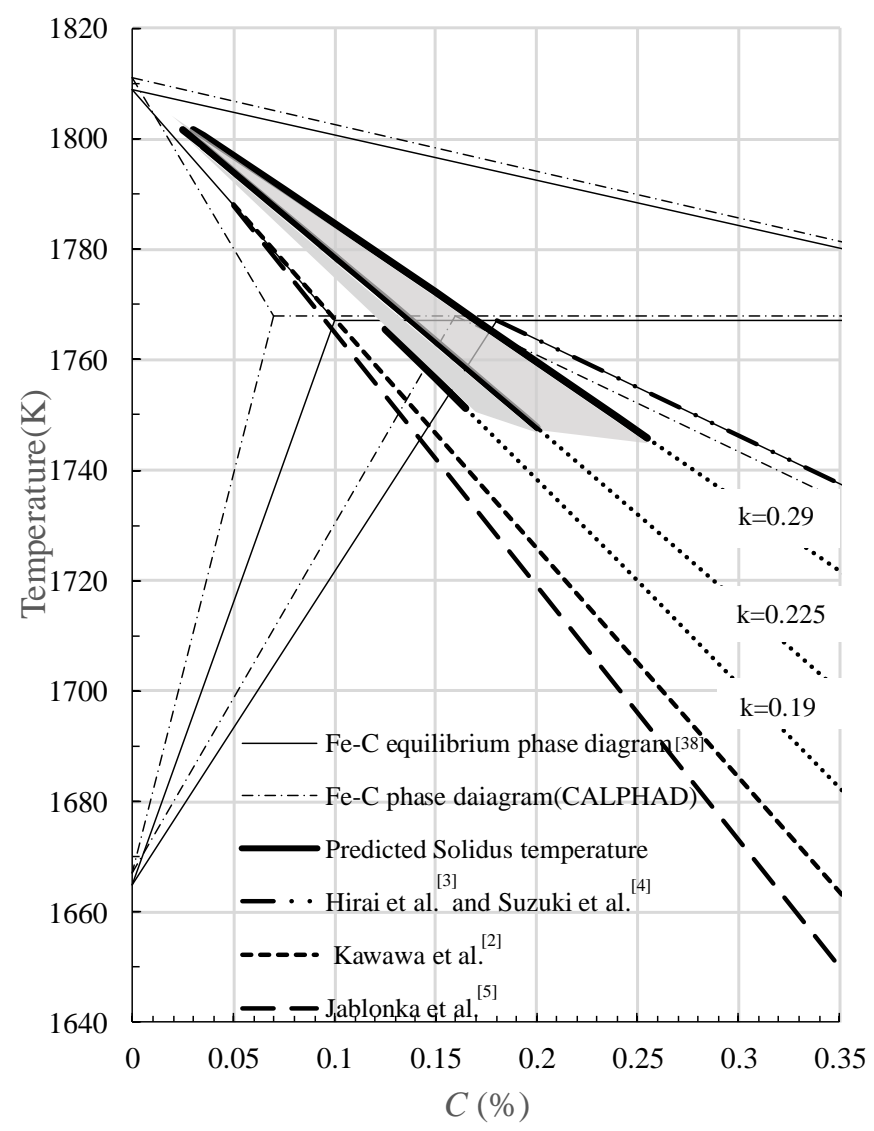

Fig. 6 Solidus temperature predicted by the model with different $\mathrm{k}$ values and the reported solidus temperature (phase diagram of a $\mathrm{Fe}-\mathrm{C}$ binary system). 


\subsection{Applications of the Present Analytical Solutions to the Steel Casting Operations}

To check the consistency between the model predictions and the actual values, the model predictions have been compared with the reported measurements by Kawawa et al. [1] adopting the shoot bullet technique for a continuously cast carbon steel (Fig. 7). The solidus positions were determined at the points where the bullets stuck with the steel shell. On the other hand, the points where the bullet fully melted and the composition became homogeneous with the molten bulk steel were defined as the liquidus positions (i.e., $f_{S}$ $=0.2-0.6)$.

It should be noted that the liquidus temperature of the present model ( $\mathrm{Fe}-\mathrm{C}$ binary alloy model) was corrected ( $5 \mathrm{~K}$ down) in accordance with the formula by Kawawa et al. [23] because of the effect of additional alloy components (i.e., $0.7 \% \mathrm{Mn}$ and $0.22 \% \mathrm{Si}$ ). This approach for low-alloyed or low-carbon steels belonging to the $\mathrm{Fe}-\mathrm{C}$ binary system was previously used by Fujimura et al. [22], and Esaka et al. [38]. The further decrease of the solidus temperature as a result of the enrichment of Mn and $\mathrm{Si}$ in the mushy zone estimated to be $3.3 \mathrm{~K}\left(3.3^{\circ} \mathrm{C}\right)$ according to the previous model for a multi-component alloy system. A $2.8 \mathrm{~K}\left(2.8^{\circ} \mathrm{C}\right)$ decrease was expected according to the formula by Esaka et al. [38] was neglected because it is low as compared to that produced by carbon enrichment (the error of solidus point, the $240 \mathrm{~s}$ after the solidification started was estimated to be $\left.2 \times 10^{-4} \mathrm{~m}\right)$. The estimated $\mathrm{k}^{\mathrm{ef}}$ value for carbon $\left(\mathrm{k}^{\mathrm{ef}}=0.9\right)$ was in good agreement with generally accepted values. As shown in Fig. 7, good agreements between the measured and the estimated liquidus $\left(f_{\mathrm{s}}=0.2-0.6\right)$ and solidus lines were also obtained.

The changes in important parameters predicted by the model for a $0.15 \% \mathrm{C}$ steel with respect to the surface temperature are shown in Fig. 8. The effective partition ratio and the solidus temperature remained nearly constant. The solidification constants of the solidus and liquidus points slightly increased with the decrease of surface temperature. Thus, increasing the shell thickness by intensive cooling is not easy and can possibly result in an increase of surface defects in cast steel as a result of intensified non-uniform water spray cooling. Thus, it is easy to study the operational actions and results with the model proposed herein. The validation of $\alpha$ that represents the homogeneity of the carbon concentration in the solid within a mushy zone along the dendrite radius direction was made as follows:

The numerical analysis regarding to the carbon redistribution by diffusion in the solid was made (Appendix III). It was assumed that a cylindrical dendrite sequentially grew up to $500 \mu \mathrm{m}$ in diameter according to $f_{s}$ and the carbon concentration at the solid/liquid interface changed according to the model 
predictions. The total solidification time from the beginning until the end of the solidification process was $213 \mathrm{~s}$. The carbon diffusion coefficient in the solid used in the calculation was $\mathrm{D}=6.6 \times 10^{-10} \mathrm{~m}^{2} / \mathrm{s}$ [39]. The carbon concentration in the solid mostly followed the enrichment of carbon in residual liquid, although a small diffusion delay in the central region was observed after the middle stage of solidification. However, the final averaged carbon concentration in the dendrite reached $97 \%$. Thus, it is considered that $\alpha$ remained close to 1 during solidification.

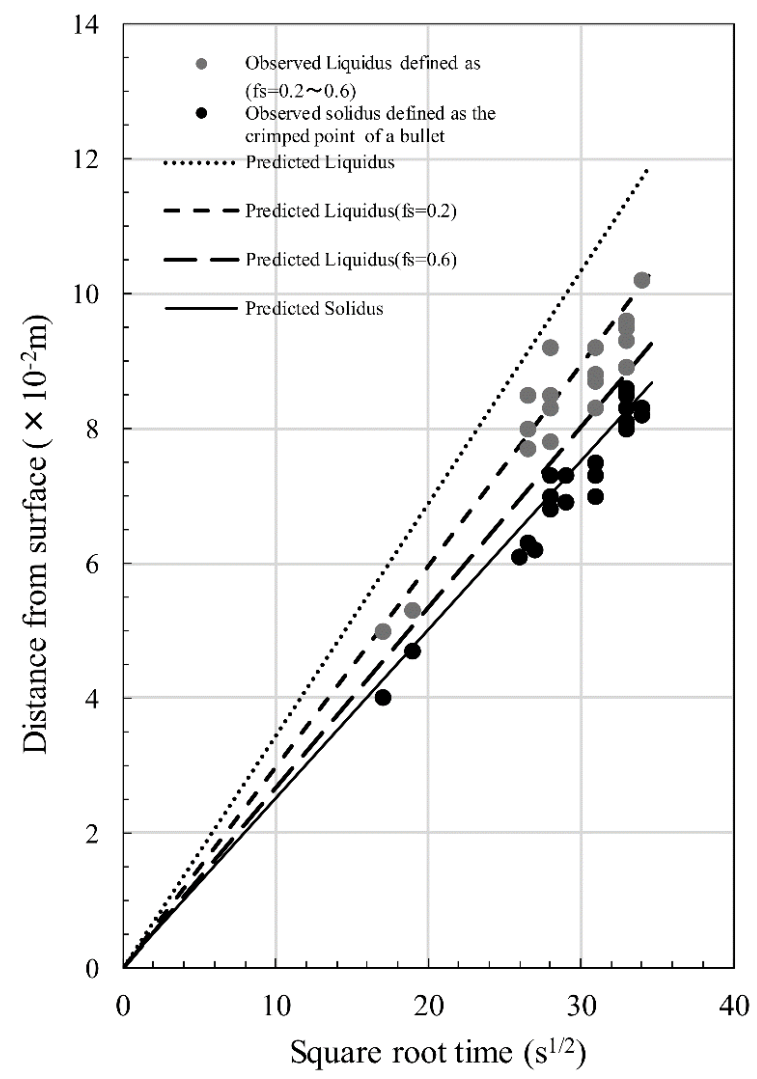

Fig. 7 Measured and estimated liquidus and solidus positions in a continuously cast steel as measured by the shoot bullet technique [1] and the model predictions (the observed liquidus positions are defined as $f_{\mathrm{s}}=0.2-0.6$. Steel composition $0.15 \% \mathrm{C}, 0.22 \% \mathrm{Si}$, and $0.70 \% \mathrm{Mn}$ ). 


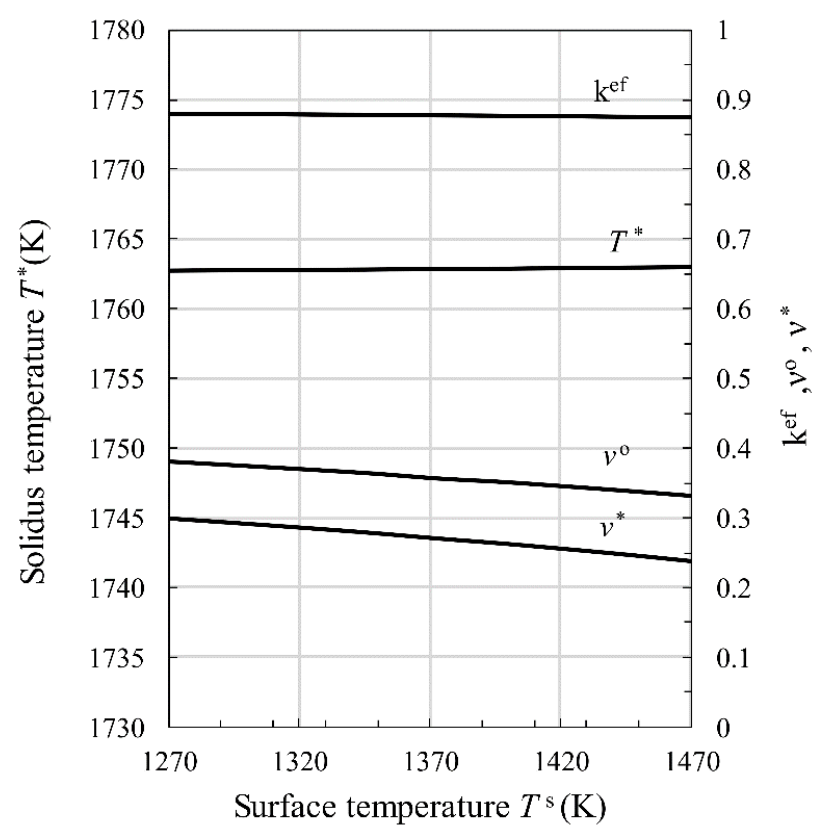

Fig. 8 Influence of the surface temperature $T^{\mathrm{s}}$ on the solidus temperature $T^{*}$, the effective partition ratio $\mathrm{k}^{\mathrm{ef}}$ and the solidification constants $v^{*}$ and $v^{\circ} .(0.15 \% \mathrm{C}, \mathrm{k}=0.225$, and the others properties are listed in Table 1).

\section{Conclusions}

The solidus temperature, parameters directly related to the solidification constants of the solidus and the liquidus points were obtained as a part of the solutions of the nonlinear heat- and solute-transfer equations assuming a linear relationship between the solid fraction and the temperature. As a result, an estimation of the temperature profile and solute concentration in the mushy zone with the overall temperature profiles in the solid and liquid is easily obtained. The model predictions were in good agreements with generally accepted values for a continuously cast steel. The solidification constants were also in the range of those of continuously cast carbon steels. Furthermore, the predicted solidus temperature lied in the intermediate temperature range between the values calculated with formulas by Hirai et al. and Suzuki et al. and those estimated by Kawawa et al. and Jablonka et al.

The analytical solutions of the model were in good agreement with the numerical analysis, and showed good consistency with the Neumann's solution at low carbon ranges. It should be noted that conventional heat analyses (e.g., the equivalent specific heat method), with the solidus temperature predicted by this model, provide the temperature and the solute concentration in the mushy zone with respect to time. The model simplifies the extensive computation to simultaneously solve the heat- and solute-transfer equations while searching for the solidus temperature and the fraction solid as part of simultaneous solutions. This model would be beneficial for simplifying the complicated analysis considering the heat- 
and solute-transfer phenomena in the mushy zone.

\section{Appendix I}

The error of the approximation of the $\operatorname{erf}(\eta)$ is kept smaller than $0.2 \%$ for $\eta>1.73$, as shown in Fig. 9 .

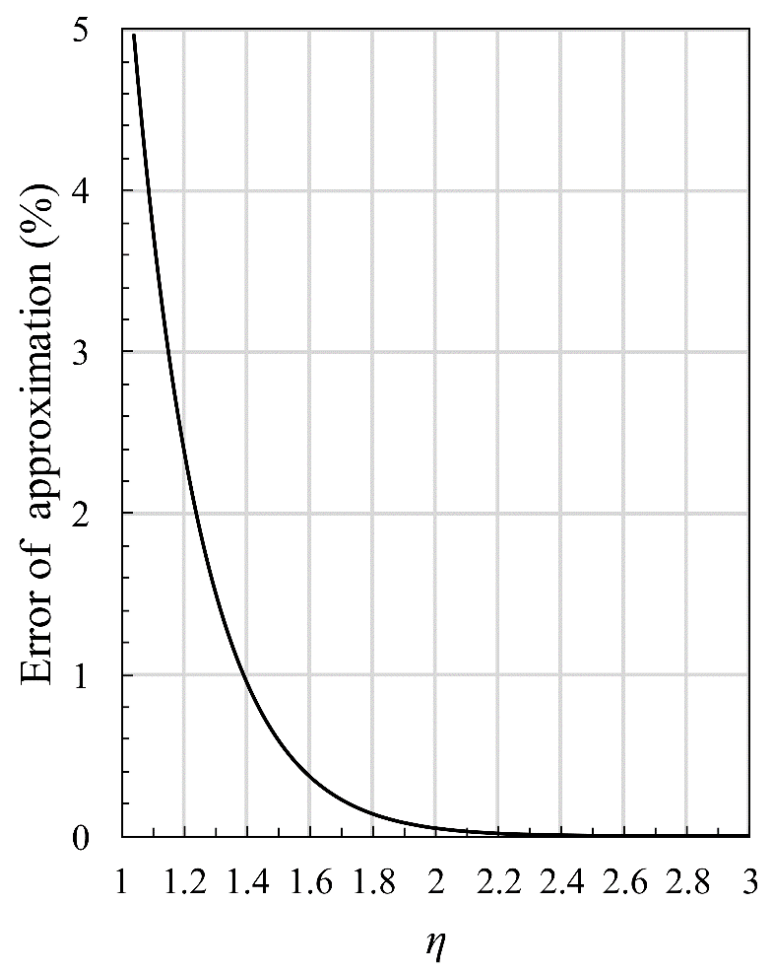

Fig. 9 Error of approximation for the $\operatorname{erf}(\eta)$ used in the model.

\section{Appendix II}

The unknown variables, important physical properties are shown in Table 3. The typical carbon partition ratio $\mathrm{k}$ in the $\delta$ phase (a wide range of values is reported) is used. The left and right sides of Eqs. (71) and (72) are denoted as A, B, and C (B is commonly used). The unknown parameters minimizing the aimed function $\mathrm{Z}$ defined as follows were sought:

$$
\mathrm{Z}=(1-\mathrm{A} / \mathrm{B})^{2}+(1-\mathrm{C} / \mathrm{B})^{2}
$$

$$
\mathrm{A}=\frac{\mathrm{K}_{1}\left(T^{*}-T^{\mathrm{s}}\right) \exp \left\{\left(1-\frac{\beta_{2}}{\beta_{1}}\right) \eta_{2}^{* 2}\right\}}{\left(T^{*}-T^{\mathrm{o}}\right) \operatorname{erf}\left(\sqrt{\frac{\beta_{2}}{\beta_{1}}} \eta_{2}^{*}\right) \sqrt{\beta_{1}}}
$$




$$
\begin{aligned}
& \mathrm{B}=\frac{\mathrm{K}_{2}}{\left\{\operatorname{erf}\left(\eta_{2}^{*}\right)-\operatorname{erf}\left(\eta_{2}^{\circ}\right)\right\} \sqrt{\beta_{2}}} \\
& \mathrm{C}=\frac{\mathrm{K}_{3}\left(T^{\mathrm{i}}-T^{\mathrm{o}}\right) \exp \left\{\left(1-\frac{\beta_{2}}{\beta_{3}}\right) \eta_{2}^{\mathrm{o} 2}\right\}}{\left(T^{*}-T^{\mathrm{o}}\right)\left\{1-\operatorname{erf}\left(\sqrt{\frac{\beta_{2}}{\beta_{3}}} \eta_{2}^{\mathrm{o}}\right)\right\} \sqrt{\beta_{3}}} \\
& \mathrm{D}: \frac{\left\{1-\operatorname{erf}\left(\eta_{2}^{\circ}\right)\right\}}{\left\{\operatorname{erf}\left(\eta_{2}^{*}\right)-\operatorname{erf}\left(\eta_{2}^{\circ}\right)\right\}}=\frac{2(1-\mathrm{k})}{(2-\mathrm{k}-\alpha \mathrm{k})} \lambda C^{\circ}+\frac{(1+\alpha) \mathrm{k}}{(2-\mathrm{k}-\alpha \mathrm{k})}-\frac{\alpha \mathrm{k} D}{E-\alpha \mathrm{k} D}
\end{aligned}
$$

First, the initial values for $T^{*}, \eta^{*}$, and $\eta^{0}$ are given. The $T^{*}$ calculated with the reported formula is used as the initial value for $T^{*}$. The initial $\eta^{\circ}$ was 1.0. The $\eta^{*}$ was given as $\eta^{*}=\gamma \eta^{\circ}$ where the initial $\gamma=0.3$. Second, the $\eta^{\circ}$ is changed to minimize $\mathrm{Z}$ for the initial $T^{*}$. Convergence is quickly obtained.

Next, $\eta^{*}$ minimizing $\mathrm{Z}$ is obtained by changing $\gamma\left(\eta^{*}=\gamma \eta^{\circ}\right)$.

Substituting $\eta^{*}, \eta^{\circ}$ obtained by the above process to the left side of Eq. (67) provides $\lambda$ (used in the right side of the Eq. (67), (D: shown above). Substituting this $\lambda$ into Eq. (9), yields the new $T^{*}$. Using this $T^{*}$ as the initial $T^{*}$ and repeating the same process mentioned above (2) to (4) yields the set of $\left(T^{*}, \eta^{*}\right.$, and $\left.\eta^{\circ}\right)$ as the three Eqs. (67), (71), and (72) match.

This process is repeated until $\mathrm{Z}<0.1$, and the four decimal digits does not change in the present analysis.

Table 3 Unknown variables and physical properties used in the model and the equations to determine unknown properties

\begin{tabular}{|c|l|c|}
\hline$T^{*}$ & Solidus Temp. & $\bigcirc$ \\
\hline$\eta_{2}{ }^{*}$ & $\eta$ for solidus point in mushy zone & $\bigcirc$ \\
\hline$\eta_{2}{ }^{\mathrm{o}}$ & $\eta$ for liquidus point in mushy zone & $\bigcirc$ \\
\hline$T^{\mathrm{o}}$ & Liquidus temp. & $\bigcirc$ \\
\hline$T^{i}$ & Initial Temp. & $\bigcirc$ \\
\hline$T^{\mathrm{s}}$ & Surface Temp. & $\bigcirc$ \\
\hline$C^{\circ}$ & Solute concentration in bulk liquid & $\bigcirc$ \\
\hline$K_{1}, K_{2}, K_{3}$ & Thermal conductictivity reported value & $\bigcirc$ \\
\hline$C p_{1}, C_{2}, C p_{3}$ & Specific heat reported value & $\bigcirc$ \\
\hline $\mathrm{m}$ & Temperature gradiant of the liquidus line & $\bigcirc$ \\
\hline $\mathrm{k}$ & Partition ratio of solute & $\bigcirc$ \\
\hline$\beta_{1}, \beta_{3}$ & Thermal properties defined by Eqs. (26),(28) & $\triangle$ \\
\hline$\beta_{2}$ & Thermal properties defined by Eq. (27) & $\triangle$ \\
\hline$\lambda, S$ & parameter detremined by Eqs. (62),(63) & $\triangle$ \\
\hline$E$ & Interdiffusion coefficient in liquid estemated by Eq. (61) & \\
\hline
\end{tabular}




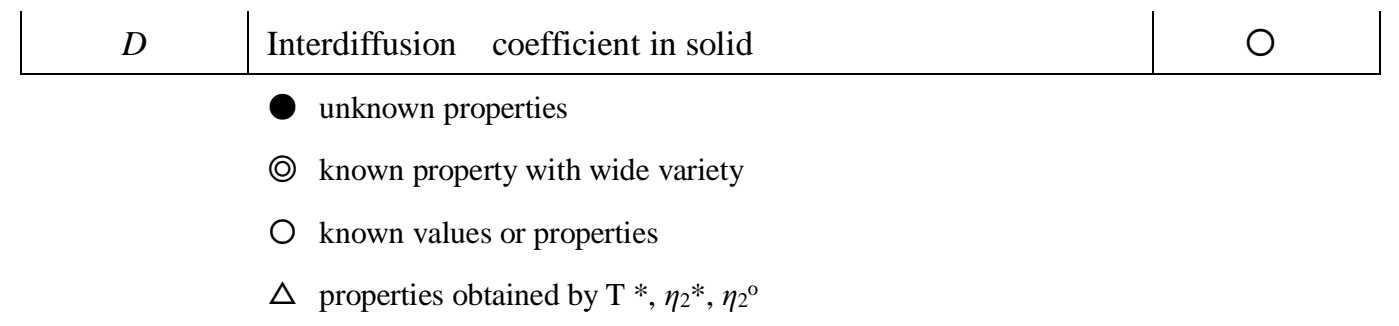

\section{Appendix III}

The carbon concentration in a cylindrical dendrite becomes almost homogeneous at the end of solidification due to the rapid diffusion, as shown in Fig. 10.

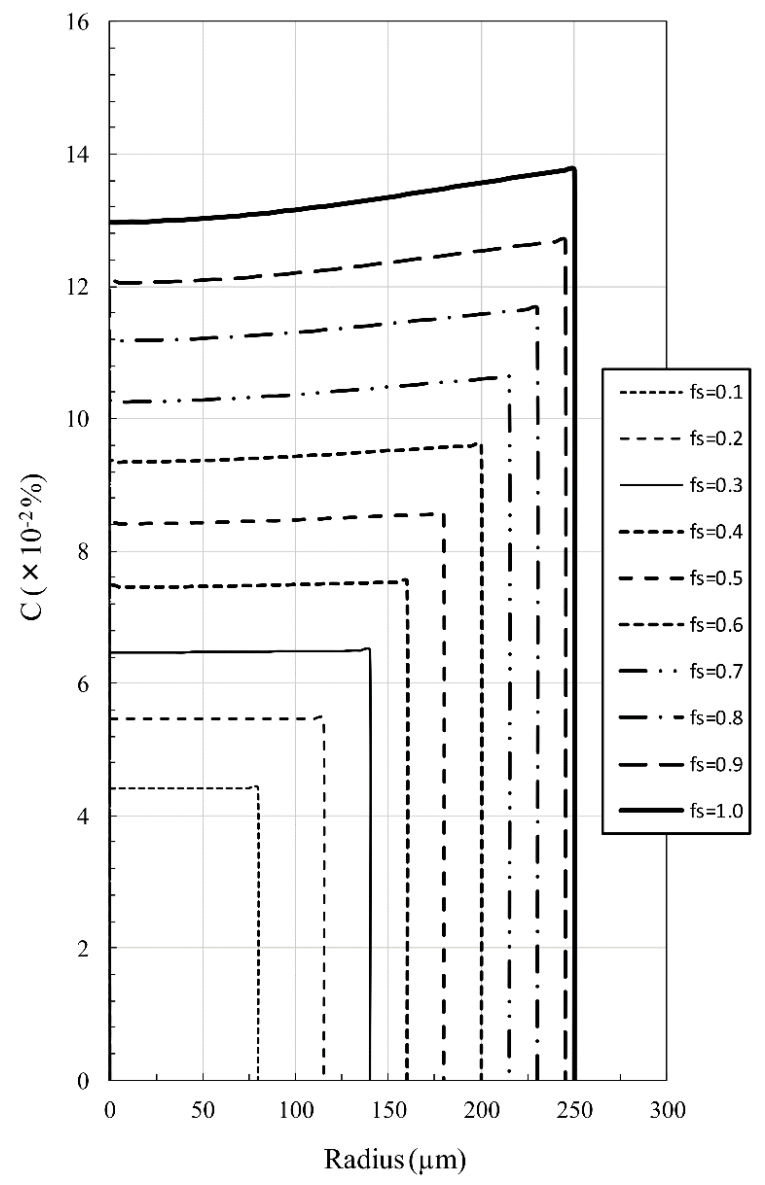

Fig. 10 Transition of $\mathrm{C}$ in the solid during the growth of a dendrite. $\mathrm{C}$ in the liquid was increased according to the model predictions. $\left(\mathrm{C} / 0.15 \%, \mathrm{Cs}_{\mathrm{s}}^{*} / 0.138 \%, D=6.6 \times 10^{-10} \mathrm{~m}^{2} / \mathrm{s}\right.$, solidification time $=213 \mathrm{~s}$, dendrite diameter $\left.=500 \mu \mathrm{m}\right)$. 


\section{References}

[1] T. Kawawa, H. Sato, S. Miyahara, T. Koyano and H. Nemoto, Determination of Solidifying Shell Thickness of Continuously Cast Slab by Rivet Pin Shooting, Tetsu-to-Hagane 60 (1974) 206216.

[2] T. Kawawa and H. Tuchida, Tekko-no-Gyouko (Solidification of steel), Appendix 4, ed. By Solidification Comm., Joint Sc. on Iron and Steel Basic Research of ISIJ, ISIJ, Tokyo, 1977.

[3] M. Hirai, K. Kanamaru and H. Mori, Tekko-no-Gyouko (Solidification of steel), Appendix 4, ed. By Solidification Comm., Joint Sc. on Iron and Steel Basic Research of ISIJ, ISIJ, Tokyo, 1977.

[4] A. Suzuki, T. Suzuki, Y. Nagaoka and Y. Iwata, On Secondary Dendrite Arm Spacing in Commercial Steels Having Different Carbon Contents, J. Jpn. Inst. Met. 32 (1968) 1301-1305.

[5] A. Jablonka, K. Harste, and K. Schwerdtfeger, Steel Res., 62 (1991) 24-33.

[6] K. Gryc, B. Smetana, M. Zaludova, K. Michalek, P. Klus, M. Tkadleckova, L, Socha, J. Dobrovska, P. Machovcak, L. Valek, R. Pachlopnik and B. Chmiel, Determination of the Solidus and Liquidus Temperatures of the Real-Steel Grades with Dynamic Thermal-Analysis Methods, Mater. Technol. 47 (2013) 569-575.

[7] E. A. Mizikar, Trans. AIME, 239 (1967) 1747-1753.

[8] J. Szekely and V. Stanek, On Heat Transfer and Liquid Mixing in the Continuous Casting of Steel, Metall. Trans. 1 (1970) 119-126.

[9] J. Matsuno, H. Nakato and H. Ohi, An analysis of Solidification Rate and Surface Temperature of Continuous Casting Slabs, Tetsu-to-Hagane 60 (1974) 1023-1032.

[10] Y. K. Chaung and K. Schwerdfeger, Arch. Eisenhüttenwes. 44 (1973) 341-347.

[11] P.H. Shingu, K. Takeshita, R. Ozaki and T. Akiyama, An analysis of the Solidification of a Binary Eutectic System Considering Temperature and Solute Distribution, J. Jpn. Inst. Met. 42 (1978) $172-179$.

[12] H.D. Brody and M.C. Flemings, Solute Redistribution during Dendritic Solidification, Trans. Met. Soc. AIME 236 (1966) 615-624.

[13] T.W. Clyne and W. Kurz, Solute Redistribution during Solidification with Rapid Solid State 
Diffusion, Met. Trans. 12A (1981) 965-971.

[14] I. Ohnaka and T. Fukusako, Calculation of Solidification of Castings by a Matrix Method, Trans. Iron Steel Inst. Jpn. 17 (1977) 410-418.

[15] K. Kumai, A. Sano, T. Ohashi, E. Nomura and H. Fujii, Study on Solidification Behavior, Solute Segregation and Fluid Flow in Continuously Cast Slab, Tetsu-to-Hagane 7 (1974) 894-914.

[16] S. Asai and I. Muchi, Analysis of Effective Distribution Coefficient Based of Transport Phenomena in Liquid and Solid Region, Tetsu du-to-Hagane 64 (1978) 1685-1692.

[17] R.N. Hills, D.E. Looper and P.H. Roberts, A Thermodynamically Consistent Model of a Mushy Zone, Q. J. Mech. Appl. Math. 36 (1983) 505-539.

[18] D.V. Alexandrov, Solidification with a Quasi-Equilibrium Mushy Region: Exact Analytical Solution of Nonlinear Model, J. Crystal Growth 222 (2001) 816-821.

[19] K. Takeshita, An Analysis of the Solidification of a Binary Eutectic System in Consideration of Both Heat and Solute Diffusion, J. Jpn. Inst. Met. 47 (1983) 647-653.

[20] H.E. Huppert and M.G. Worster, Dynamic Solidification of a Binary Melt, Nature 314 (1985) 703-707.

[21] D.V. Alexandrov and V.P. Malygin, Self-Similar Solidification of an Alloy from a Cooled Boundary, Int. J. Heat Mass. Transf. 49 (2006) 763-769.

[22] T. Fujimura and J.K. Brimacombe, Mathematical Analysis of Solidification Behavior of Multicomponent Alloys, Trans. Iron Steel Inst. Jpn. 26 (1986) 532-539.

[23] T. Kawawa, Tekko-no-Gyouko (Solidification of steel), Appendix 4, ed. By Solidification Comm., Joint Sc. on Iron and Steel Basic Research of ISIJ, ISIJ, Tokyo, 1977.

[24] H.S. Carslaw and J.G. Jaeger, Conduction of Heat in Solids, 2nd ed., Oxford University Press, New York, Tronto, Tokyo, 1959, 283-291.

[25] T. Mitsuo, T. Horigome, S. Saito, E. Nomura, Y. Kitamura and R. Kohno, On the Accumulation Mechanism and the Reducing Process of Large Non-Metalic Inclusions in the Bottom Equiaxed Zone of Ingots, Tetsu-to-Hagane 57 (1971) 915-941.

[26] M. C. Flemings and G. E. Nero, Trans. Met. Soc. AIME, 239 (1967) 1449-1461.

[27] H. Nomura, T. Tarutani and K. Mori, Mathematical Model of Formation of Segregation Zone Caused by Volume Change in Solidification of Iron Alloys, Tetsu-to-Hagane 67(1981) 80-87. 
[28] K. Miyazawa, STA, vol. 2 (2001) 59-65.

[29] K. Harste, Investigation of the Shrinkage and the Origin of Mechanical Tension Solidification and Successive Cooling of Cylindrical Bars of Fe-C alloys, PhD. Dissertation, Universität Clausthal,1989

[30] Y.A. Meng and B.G. Thomas, Heat-Transfer and Solidification Model of Continuous Slab Casting: CON1D, Metall. Mate. Trans. B34 (2003) 685-705.

[31] A. Hays and J. Chipman, Mechanism of Solidification and Segregation in a Low-Carbon Rimming -Steel Ingot, Trans. Met. Soc. AIME 135 (1938) 85.

[32] W.A. Fisher, H. Splizer and M. Hishinuma, Das Zonenschmelzen von Eisen und die Ermittlung der Verteilungskoeffizienten für Kohlenstoff, Phosphor, Schwefel und Sauerstoff, Arch. Eisenhüttenwes. 31 (1960) 365-371.

[33] C. E. Sims, Electric Furnace Steelmaking, vol. 2, John Wiley \& Sons, 1962, p. 99.

[34] W.A. Tiller, Solute Segregation during Ingot Solidification, J. Iron Steel Inst. 192 (1959) 338350.

[35] K. Katayama and S. Hattori, Trans. JSME 40 (1974) 1404-1411.

[36] R. A. Buckley and W. Hume-Rothery, J. Iron Steel Inst. 196 (1960) 403-406.

[37] R.E. Grace and G. Derge, Diffusion of Third Elements in Liquid Iron Saturated with Carbon, Trans. Metall. Soc. AIME 212 (1958) 313-337.

[38] R. Tanaka, On the Recent Iron-Carbon Equilibrium Diagram, Tetsu-to-Hagane 53 (1967) 15861604.

[39] H. Esaka and S. Ogibayashi, Estimation of Primary Dendrite Arm Spacing and Solidified Interface Morphology in Low Carbon Steel by Introducing Quasi Fe-C Binary Alloy, Tetsu-toHagane 84 (1998) 49-54.

[40] D.F. Kalinovich, I.I. Kovenskii and M.D. Smolin, Carbon State in Austenite with 0, 4 and 0,6 Weight Percent Content of C, Izv. Vyssh. Ucheb. Zaved., Fiz. 9 (1971) 116. 